Check for updates

Cite this: RSC Adv., 2019, 9, 14188

\title{
Vertical alignment of liquid crystals on plant-based vanillin derivative-substituted polystyrene films
}

\author{
Changha Ju, $\uparrow$ Chanhyuk Park, $\uparrow$ Taehyung Kim and Hyo Kang (D) *
}

\begin{abstract}
To investigate the alignment behavior of liquid crystal (LC) molecules, we synthesized a series of vanillin derivative-substituted polystyrene films (PVAN\#, \# = 20,40,60,80, and 100), where \# is the substitution ratio (\%) of the vanillyl butyl ether (VAN) moiety as one of the bio-renewable vanillin derivatives. In general, a vertical LC alignment was observed in the LC cell fabricated using the polymer film having a higher molar content of VAN. Moreover, the surface energies of these polymer films were strongly related to the vertical LC alignment behavior. For example, a uniform vertical alignment was observed when the polar surface energy of the polymer was lower than approximately $2.05 \mathrm{~mJ} \mathrm{~m}^{-2}$, induced by the nonpolar and long carbon groups in the plant-based vanillin moiety. The LC cell fabricated using PVAN100 had good electrooptical characteristics such as voltage holding ratio and residual direct-current voltage and stable alignment under extreme external conditions.
\end{abstract}

Received 8th April 2019

Accepted 2nd May 2019

DOI: $10.1039 / \mathrm{c} 9 \mathrm{ra02629k}$

rsc.li/rsc-advances

that the rubbing method aligns the polymer chains anisotropically on the substrate; the LC is aligned through physicochemical interactions between the polymer chain and LC molecules. ${ }^{14}$ The rubbing method using a polymer is particularly attractive owing to the feasibility for mass large-area production and softness for flexible applications. ${ }^{15}$ For example, polyimide derivatives are most commonly employed as LC alignment layers through the rubbing process, as they provide a very stable LC alignment. ${ }^{3,16-24}$ Polyimide derivatives having long alkyl or alkyloxy groups, such as semiflexible copolyimides containing $n$-octadecyl side groups and polyimides with (n-decyloxy)biphenyloxy side groups, exhibit vertical LC alignment behaviors. ${ }^{25-28}$ Polystyrene (PS) derivatives containing long alkyl chains can also produce vertical LC alignment layers. For example, LC cells fabricated using nematic LC and rubbed polymer films of $n$-alkylsulfonylmethyland $n$-alkylthiomethyl-substituted PSs having more than 8 carbons (number of alkylcarbons $>8$ ) exhibit vertical LC alignment properties. ${ }^{29}$ LC cells consisting of 4-alkylphenoxymethylsubstituted PSs exhibit vertical LC alignment behaviors even at a very high rubbing density of 250 , regardless of the length of the alkyl side groups. ${ }^{30}$

Vanilla attracts significant attention as it is one of the most popular flavors and improves the perception of many flavors. ${ }^{31}$ Vanillyl butyl ether (VAN) is not only one of the eco-friendly and nontoxic substances but also a major contributor to the characteristic flavor and fragrance of vanilla. The use of VAN has been proposed in diverse fields as a mild warming agent providing a warming sensation and enhancing the blood circulation. ${ }^{32,33}$ VAN has a methoxy phenol with a butyl ether group. In this structure, the hydroxy group of the phenyl ring has antioxidant and antimicrobial characteristics. ${ }^{34-36}$ VAN can

Department of Chemical Engineering, Dong-A University, 37 Nakdong-Daero 550 beon-gil, Saha-gu, Busan 49315, Republic of Korea. E-mail: hkang@dau.ac.kr; Fax: +82 51200 7728; Tel: +8251200 7720

$\dagger$ These authors contributed equally to this work. 
also be used to modify the surfaces of substrates such as metal and glass using the hydroxy group through primary and secondary bondings for various film applications. Furthermore, the wettability on the surface of the film modified with VAN can be also controlled by changing the VAN content. ${ }^{37,38}$

In this study, vanillin derivative-substituted polystyrenes (PVAN\#) were synthesized to obtain the vertical alignment of the LCs. We also investigated the optical and electrical properties of LC cells fabricated using the polymer films as well as the effect of the substitution ratio of the side group on the LC alignment behavior.

\section{Experimental}

\subsection{Materials}

Vinylbenzyl chloride, vanillyl butyl ether, and potassium carbonate were purchased from Aldrich Chemical Co. MLC6608 (extraordinary refractive index $n_{\mathrm{e}}=1.5586$, ordinary refractive index $n_{\mathrm{o}}=1.4756$, dielectric anisotropy $\Delta \varepsilon=-4.2$ ), a nematic LC, was purchased from Merck Co. Several chemical agents were used in the following purification process. $N, N^{\prime}$ Dimethylacetamide (DMAc) and ethanol were dried with molecular sieves $(4 \AA)$ to remove impurities such as moisture. For the same purpose, tetrahydrofuran (THF) was used after drying by refluxing with benzophenone and sodium, followed by a distillation process. To remove some impurities and inhibitors such as tert-butylcatechol and nitroparaffin, vinylbenzyl chloride was used after column chromatography on a silica gel using hexane as an eluent. Poly(vinylbenzyl chloride) (PVBC, $M_{\mathrm{n}}=22000, M_{\mathrm{w}} / M_{\mathrm{n}}=2.02$ ) was polymerized by conventional free radical polymerization of the purified vinylbenzyl chloride using 2,2'-azoisobutyronitrile (AIBN) in a nitrogen atmosphere. The AIBN (Junsei Chemical Co., Ltd.) was purified by crystallization using methanol.

\subsection{Preparation of PVAN\#}

PVAN\# samples were synthesized by following where \# represents the substitution ratio (\%) of the VAN moiety as one of the vanillin derivatives. Representatively, the synthesis of PVAN100 is presented. PVBC $(1 \mathrm{~g}, 6.56 \mathrm{mmol})$ was dissolved in $30 \mathrm{~mL}$ of DMAc. VAN (2.07 g, $9.83 \mathrm{mmol}, 150 \mathrm{~mol} \%$ compared with PVBC) and potassium carbonate $(1.631 \mathrm{~g}, 11.81 \mathrm{mmol}, 180 \mathrm{~mol} \%$ compared with PVBC) were dissolved in $30 \mathrm{~mL}$ of DMAc. The PVBC solution was carefully poured into the other solution and then the mixed solution was magnetically stirred at $75^{\circ} \mathrm{C}$ under a nitrogen atmosphere for $24 \mathrm{~h}$. The synthesized mixture was precipitated in a large amount of methanol to obtain a white precipitate. The precipitate was dissolved again in DMAc, reprecipitated several times with methanol, and then washed with hot methanol to remove potassium carbonate and remaining salts. PVAN100 was obtained after drying overnight in a vacuum. The degree of substitution of chloromethyl to VAN was determined to be approximately $100 \%$ within the experimental error, while the yield of the product was approximately $80 \%$.
${ }^{1} \mathrm{H}-\mathrm{NMR}$ of PVAN100 [400 $\left.\mathrm{MHz}, \mathrm{CDCl}_{3}, \delta / \mathrm{ppm}\right]: \delta=0.8-1.5$ $(10 \mathrm{H}), 3.2-3.5(2 \mathrm{H}), 3.7-3.9(3 \mathrm{H}), 4.3-4.5(2 \mathrm{H}), 4.7-5.1(2 \mathrm{H}), 6.2-$ $7.2(7 \mathrm{H})$.

PVAN80, PVAN60, PVAN40, and PVAN20 were synthesized by the same procedure used for the preparation of PVAN100 except for the differences in the amount of VAN in the reaction $(1.10 \mathrm{~g}$ (5.21 mmol), $0.82 \mathrm{~g}$ (3.92 $\mathrm{mmol}), 0.54 \mathrm{~g}(2.59 \mathrm{mmol})$, and $0.27 \mathrm{~g}$ (1.30 mmol), respectively).

\subsection{Film preparation and LC cell assembly}

The coating solutions were prepared by dissolving PVAN\# in THF to a concentration of $1 \mathrm{wt} \%$. These solutions were filtered using a polytetrafluoroethylene syringe filter with a pore size of $0.45 \mu \mathrm{m}$. Using these solutions, glass plates were spin-coated at $2000 \mathrm{rpm}$ for $60 \mathrm{~s}$ to obtain thin films of the polymers. The LC cells were fabricated by assembling the films together using spacers with thicknesses of $4.25 \mu \mathrm{m}$. The cells were filled with the nematic LC, MLC-6608, and then sealed with epoxy glue.

\subsection{Instrumentation}

The synthesized polymer was analyzed by measuring the proton nuclear magnetic resonance $\left({ }^{1} \mathrm{H}-\mathrm{NMR}\right)$ using a Bruker AVANCE spectrometer at $300 \mathrm{MHz}$. The optical transmittances of the polymer films onto the glass plates were evaluated using UVvisible spectroscopy (Perkin Elmer Lamda 20 spectrometer). The contact angles of the polymer films were measured using a contact-angle analyzer, Kruss DSA10, equipped with a dropshape analysis software. The surface energy was calculated using the Owens-Wendt equation:

$$
\gamma_{\mathrm{sl}}=\gamma_{\mathrm{s}}+\gamma_{1}-2\left(\gamma_{\mathrm{s}}^{\mathrm{d}} \gamma_{1}^{\mathrm{d}}\right)^{1 / 2}-2\left(\gamma_{\mathrm{s}}^{\mathrm{p}} \gamma_{1}^{\mathrm{p}}\right)^{1 / 2}
$$

where $\gamma_{1}, \gamma_{\mathrm{sl}}$, and $\gamma_{\mathrm{s}}$ are the surface energy of the liquid, interfacial energy of the solid/liquid interface, and surface energy of the solid, respectively, and $\gamma_{1}^{\mathrm{d}}$ and $\gamma_{\mathrm{P}}^{\mathrm{P}}$ are the test liquids; $\gamma_{\mathrm{s}}^{\mathrm{d}}$ and $\gamma_{\mathrm{s}}^{\mathrm{p}}$ can be calculated using the measured static contact angles. ${ }^{39}$ Polarized optical microscopy (POM) images of the LC cells were acquired using an optical microscope (Nikon, ECLIPSE E600 POL) equipped with a polarizer and digital camera (Nikon, COOLPIX995). The voltage holding ratio (VHR) was measured by a VHR measurement system using an autronic-MELCHERS VHRM 105 instrument at a data voltage, pulse width, and frame frequency of $1.0 \mathrm{~V}, 64 \mu \mathrm{s}$, and $60 \mathrm{~Hz}$, respectively. The measurement temperatures were 25 and $60{ }^{\circ} \mathrm{C}$. The residual DC voltage (R-DC) was evaluated using a capacitance-voltage $(C-V)$ hysteresis method by Nissan Chemical Industries, Ltd.

\section{Result \& discussion}

\subsection{Synthesis and characterization of vanillin derivatives- substituted polystyrene}

Fig. 1 shows the synthesis routes for PVAN\#, where \# is the substitution ratio (\%) of VAN side groups. Substitution ratio of chloromethyl to VAN of almost $100 \%$ was obtained. The chemical structure of PVAN100 was confirmed by the ${ }^{1} \mathrm{H}-\mathrm{NMR}$ spectrum, which indicated the presence of protons from the 
<smiles>Cc1ccc(CCl)cc1</smiles>

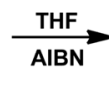<smiles>CC(C)(C)c1ccc(CCl)cc1</smiles>

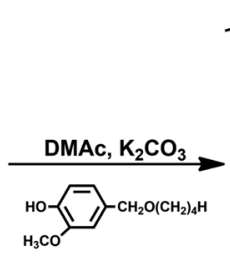

PVBC

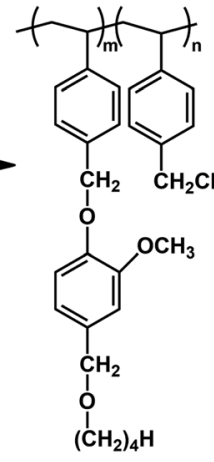

PVAN\#
Fig. 1 Synthetic route to vanillin derivatives-substituted polystyrene (PVAN\#), where \# indicates the substitution ratio of vanillyl butyl ether containing monomeric units in the polymer.

phenyl ring of the styrene backbone $(\delta=6.2-7.2$ parts per million ( $\mathrm{ppm})$ ). The proton peaks of the vanillin-derivative side chains ( $\delta=6.6-6.9,4.3-4.5,4.7-5.1$, and 3.2-3.5 ppm) indicate the inclusion of vanillin derivative moieties in the polymer. The content of VAN could be calculated by comparing the integration values of the proton peaks of the VAN $(\delta=6.6-6.9,4.3-4.5$, 4.7-5.1, and 3.2-3.5 ppm) and chloromethyl side chains $(\delta=$ 4.7-5.1 ppm). Similar integrations and calculations for PVAN80, PVAN60, PVAN40, and PVAN20 were performed and the results were generally within $\pm 10 \%$ of the values expected for stoichiometric reactions.

\subsection{Thermal behaviors of vanillin derivatives-substituted polystyrene}

The thermal behaviors of PVAN\# were measured using differential scanning calorimetry (DSC). Fig. 2 shows DSC thermograms of the polymers (PVAN\#). Owing to the presence of only one glass transition, observed in the DSC thermograms, all of the polymers had amorphous structures. The glass transition temperature $\left(T_{\mathrm{g}}\right)$ of the polymer decreased from 108 to $24{ }^{\circ} \mathrm{C}$ with the increase in the substitution ratio of VAN. In general, the polarity, flexibility, and bulkiness of the side groups of a polymer affect its $T_{\mathrm{g}}$. The strong polarity of the side group can increase $T_{\mathrm{g}}$ of the polymer, ${ }^{40}$ while the large steric volume of the

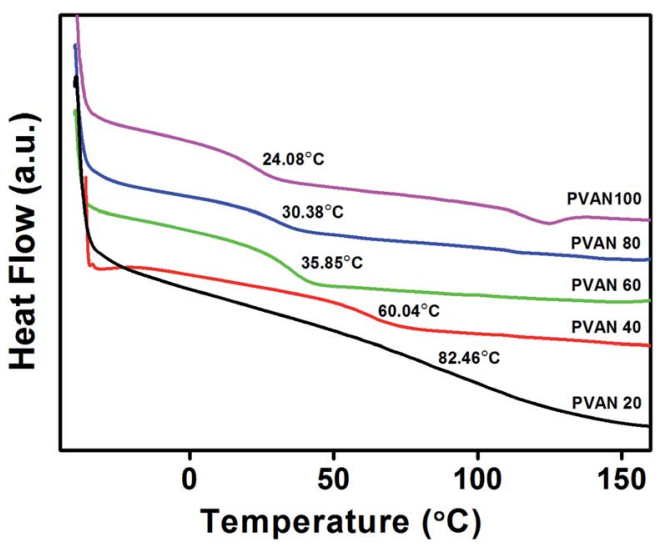

Fig. 2 DSC thermogram of PVAN\#. side group can increase or decrease $T_{\mathrm{g}}$ of the polymer. For example, $T_{\mathrm{g}}$ of poly(vinylnaphthalene) having a relatively large steric volume of substituents, such as naphthalene, is higher than that of PS. ${ }^{40}$ This implies that the incorporation of VAN with the relatively large steric volume may affect the flexibility of the polymer backbone and lead to a decrease in $T_{\mathrm{g}}$ (Table 1). ${ }^{41-43}$

\subsection{Transmittance of vanillin derivatives-substituted polystyrene films}

Fig. 3 shows transmittance spectra of the PVAN\# and PVBC films in the visible range, which can be used to evaluate the potential for surface coating applications. The transmittances of the coated PVAN\# and PVBC films onto the glass plates are higher than $94 \%$ in the visible range of $400-800 \mathrm{~nm}$. The spectrum shows that the transmittance of the PVAN\# film is superior to that of the polyimide film having the intrinsic yellowish coloration problem related to the diimide fragment conjugation as a LC alignment layer at the same visible range. In other words, the transmittances of the PVAN\# films are higher than that of the polyimide film at the same visible range. Therefore, the PVAN\# films are promising optical materials for electrooptical devices.

\subsection{Liquid crystal alignment behavior of the LC cells} fabricated with vanillin derivatives-substituted polystyrene films

Photographs of the LC cells consisting of the copolymers (PVAN\#) are shown in Fig. 4. The LC cells consisting of the

Table 1 Reaction conditions and results for the synthesis of the PVBC and PVAN\#

\begin{tabular}{lccr}
\hline $\begin{array}{l}\text { Polymer } \\
\text { designation }\end{array}$ & $\begin{array}{l}\text { Vanillyl butyl } \\
\text { ether (mol\%) }\end{array}$ & $\begin{array}{l}\text { Degree of } \\
\text { substitution }(\%)\end{array}$ & $T_{\mathrm{g}}$ \\
\hline PVBC & - & - & 108 \\
PVAN20 & 20 & 20 & 82 \\
PVAN40 & 40 & 40 & 60 \\
PVAN60 & 60 & 60 & 36 \\
PVAN80 & 80 & 80 & 30 \\
PVAN100 & 150 & 100 & 24
\end{tabular}

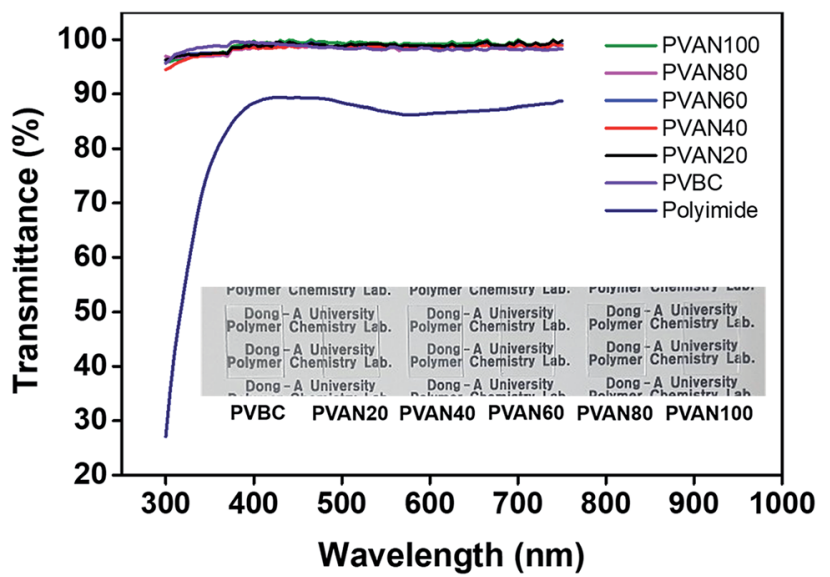

Fig. 3 UV-Vis transmittance spectra of PVAN\# and PVBC and polyimide alignment layer onto quartz substrates. 


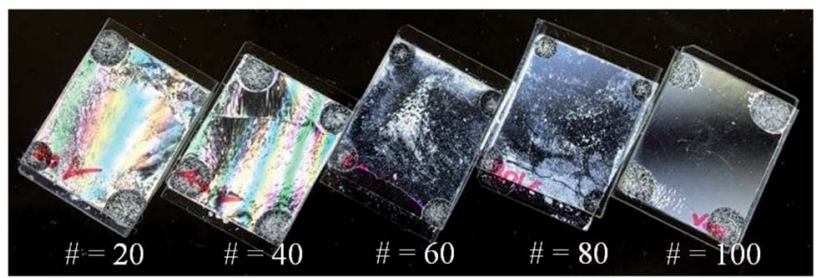

Fig. 4 Photograph images of the LC cells fabricated with PVAN\# films according to the molar content of vanillyl butyl ether moiety.

PVAN\# films having substitution ratios of vanillin derivatives smaller than approximately $80 \mathrm{~mol} \%$ (PVAN20, PVAN40, PVAN60, and PVAN80) exhibited LC textures with a partial birefringence. On the other hand, a very high uniformity of the vertical LC alignment was observed in the POM image of the LC cell consisting of the polymer film having the vanillin derivative substitution ratio of $100 \mathrm{~mol} \%$ (PVAN100). In repeated experiments, the vertical LC alignment of PVAN100 was reproducible. In addition, the vertical LC alignment was maintained for at least one year since we fabricated the LC cells using the polymers.

The LC alignment behaviors of the LC cells consisting of the PVAN\# films were investigated by POM images to analyze the orientations of the LC molecules on the PAN\# films (Fig. 5). A random planar LC alignment was observed for the LC cell fabricated using the PVBC film (data not shown). When the molar content of the vanillin derivatives substituted on PVBC was smaller than $40 \%$, random planar LC alignments were also observed in the LC cells (with PVAN20 and PVAN40 films), according to conoscopic POM images. On the other hand, when the molar contents of the vanillin derivatives substituted on PVBC were 60 and $80 \%$, partial vertical LC alignments were observed in the LC cells with the PVAN60 and PVAN80 films. Only the PVAN100 film provided a stable uniform vertical orientation layer.

\subsection{Surface properties of vanillin derivatives-substituted polystyrene films}

According to the LC cell images, the polymers with higher substitution ratios of vanillin derivatives have a general trend to exhibit vertical LC alignment. We investigated the LC alignment behaviors of the PVAN\# films using surface characterization techniques such as surface energy measurement. The surface energies of the polymer films obtained based on the static contact angles of water and diiodomethane were investigated (Fig. 6 and Table 2). The total surface energies of all of the polymer films were calculated summation of the polar surface energy and dispersion surface energy. The polar surface energies could affect the vertical alignment behaviors of the LCs on

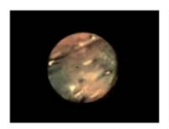

PVAN20

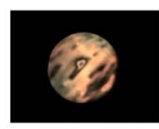

PVAN40

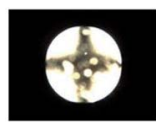

PVAN60

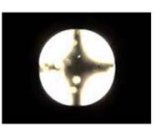

PVAN80
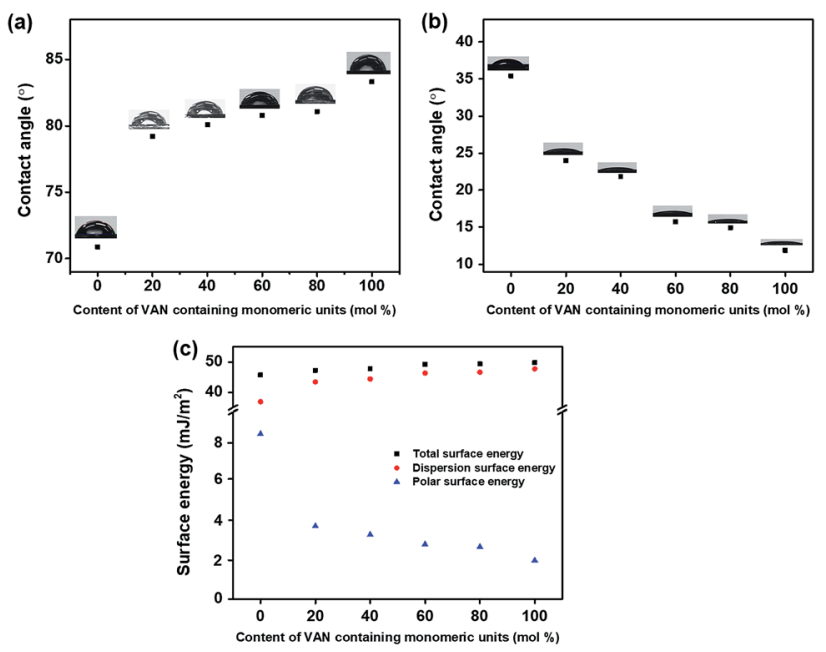

Fig. 6 (a) Water, (b) diiodomethane contact angle, and (c) surface energy values of PVAN\# films according to the molar content of the vanillyl butyl ether moiety in the side groups.

the PVAN\# series. With the increase in the molar content of the vanillin derivatives on the polymer film, the polar surface energy decreased (PVBC $\left(8.83 \mathrm{~mJ} \mathrm{~m}^{-2}\right)$, PVAN20 $\left(3.89 \mathrm{~mJ} \mathrm{~m}^{-2}\right)$, PVAN40 $\left(3.43 \mathrm{~mJ} \mathrm{~m}^{-2}\right)$, PVAN60 $\left(2.91 \mathrm{~mJ} \mathrm{~m}^{-2}\right)$, PVAN80 $(2.78 \mathrm{~mJ}$ $\left.\mathrm{m}^{-2}\right)$, and PVAN100 $\left.\left(2.05 \mathrm{~mJ} \mathrm{~m}^{-2}\right)\right)$. The critical polar surface energy inducing the uniform vertical LC alignment was approximately $2.05 \mathrm{~mJ} \mathrm{~m}^{-2}$ (polar surface energy of the PVAN100 film). As vanillin has a relatively nonpolar and bulky group, not only the two phenyl groups but also the 4-butoxymethyl moiety attached to the para-position at the 2-methoxyphenyl group. Therefore, the increase in the degree of substitution of VAN leads to a decrease in the polar surface energy determining the formation of the vertical LC orientation. We believe that the vertical LC orientation was well correlated with the polar surface energy component of the LC alignment film. ${ }^{44-46}$ It is reasonable to conclude that the vertical LC orientation behavior on the PVAN100 film is attributed to the increased steric repulsions between the LC molecules and polymer surface owing to the incorporation of the bulky vanillin into the side group of the PS and low polar surface energy originating from the unique chemical structures of the nonpolar and long carbon groups.

\subsection{Reliability and electro-optical performance of the $\mathrm{LC}$} cells fabricated with vanillin derivatives-substituted polystyrene films

Further, the reliabilities of the LC cells consisting of the PVAN100 films inducing the uniform vertical LC alignments were investigated by a stability test of the LC alignment behaviors under harsh external conditions such as a high temperature and UV irradiation. The thermal and UV stabilities were analysed by conoscopic POM images after heat treatment $\left(100,150\right.$, and $\left.200^{\circ} \mathrm{C}\right)$ for $10 \mathrm{~min}$ and UV treatments $(10,20$, and $30 \mathrm{~J} \mathrm{~cm}^{-2}$ ) of the LC cell, respectively. As shown in Fig. 7, the PVAN100 film after the heat and UV treatments still maintained the vertical LC aligning ability as no distinguishable difference 
Table 2 Surface energy values and LC alignment properties of the polymers

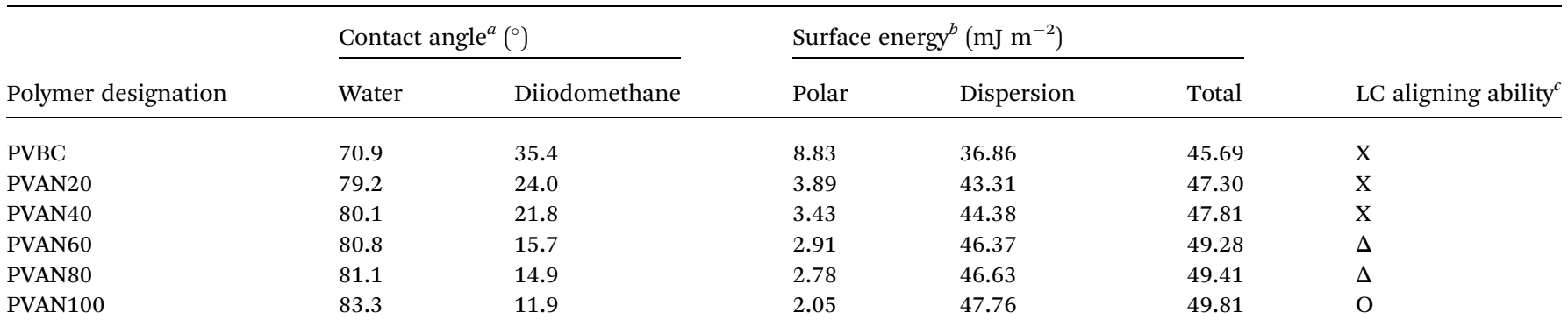

${ }^{a}$ Measured from static contact angles. ${ }^{b}$ Calculated from Owens-Wendt's equation. ${ }^{c}$ Circle $(\mathrm{O})$ and triangle $(\Delta)$ and cross $(\mathrm{X})$ indicate polymer film have uniform vertical and partial vertical and planar LC aligning ability, respectively.

in maltese crosspattern in the conoscopic POM image was observed. The polar surface energies of the PVAN100 film obtained based on the static contact angles of water and diiodomethane were also measured after the heat and UV treatments. When the temperature was increased to $200{ }^{\circ} \mathrm{C}$ and the UV energy was increased to $30 \mathrm{~J} \mathrm{~cm}^{-2}$, the polar surface energy (one of the surface properties) of the PVAN100 film was in the range of approximately $1.97-2.13 \mathrm{~mJ} \mathrm{~m}^{-2}$. Therefore, the PVAN100 LC cell had good thermal and UV stabilities in terms of the vertical LC alignment.

The electro-optical performance of the LC cell fabricated using the PVAN100 film was measured to evaluate the potential for LCD applications including flexible applications. The LC cell exhibited a VHR above $99 \%$ at $25{ }^{\circ} \mathrm{C}$, which was sustained at $60{ }^{\circ} \mathrm{C}$. This value is sufficiently high for applications as the LC alignment layer in thin-film transistor LCDs. ${ }^{7}$ The R-DC of the LC cell obtained using the $C-V$ hysteresis method was very low (smaller than $15 \mathrm{mV}$ ), smaller than those of the commercial polyimides. ${ }^{7}$ The VHR and R-DC of the LC cell fabricated using the PVAN100 film were attributed to the unique characteristics of the hydrocarbonated polymers such as the low dielectric constant.

Recently, the development of plastic substrates for flexible LCDs has attracted significant attention. ${ }^{47}$ According to conoscopic images, LC cells fabricated using the PVAN\# films on polyethylene terephthalate plates exhibited similar LC alignment

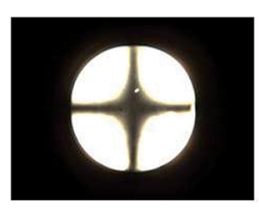

$100{ }^{\circ} \mathrm{C}$

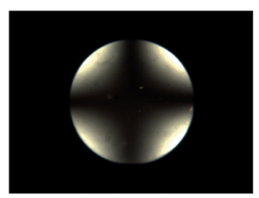

$10 \mathrm{~J} / \mathrm{cm}^{2}$

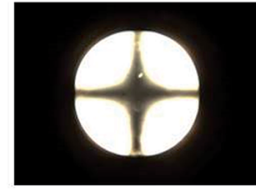

$150{ }^{\circ} \mathrm{C}$

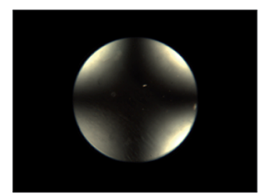

$20 \mathrm{~J} / \mathrm{cm}^{2}$

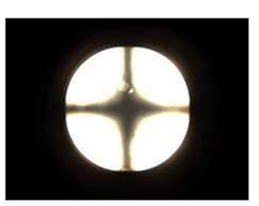

$200{ }^{\circ} \mathrm{C}$

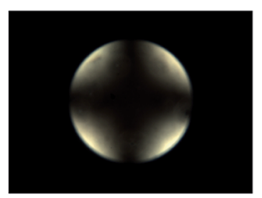

$30 \mathrm{~J} / \mathrm{cm}^{2}$
Fig. 7 Conoscopic POM images of the LC cells made from PVAN100 films, observed after external conditions; heat treatment at 100, 150, and $200{ }^{\circ} \mathrm{C}$ for $10 \mathrm{~min}$ and ultraviolet at 10,20 , and $30 \mathrm{~J} \mathrm{~cm}^{-2}$, respectively.

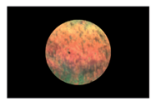

PVAN20

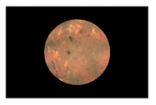

PVAN40

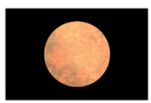

PVAN60

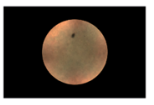

PVAN80

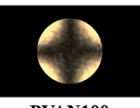

PVAN100
Fig. 8 Conoscopic POM images of the LC cells made from PVAN\# films on PET (polyethylene terephthalate) substrates according to the molar content of vanillyl butyl ether moiety.

behaviors to those of the LC cells fabricated using the same polymer films on the glass plates (Fig. 5). Therefore, the plantbased PVAN\# is a promising LC alignment film for flexible LC applications, e.g., in the vertical alignment mode (Fig. 8).

\section{Conclusions}

A series of PS derivatives containing VAN (PVAN\#), one of the plant-based vanillin derivatives, were synthesized to investigate the LC alignment behaviors of these polymer films. The PVAN\# polymer films exhibited superior optical transparencies in the visible range (400-800 nm). For example, the transmittance (98.9\%) of the PVAN100 film onto the glass plate at $500 \mathrm{~nm}$ was better than that $(80.5 \%)$ of the polyimide film, which is the most commonly used LC alignment layer. The uniform vertical LC alignment was observed in the LC cell fabricated using the PVAN100 film. Partial vertical LC alignment behaviors were observed for the LC cells fabricated using the films of PVAN60 and PVAN80. Random planar LC alignment behaviors were observed for the LC cells with the PVAN20 and PVAN40 films. The vertical LC alignment behavior was well correlated with the polar surface energy of the polymer film. The vertical alignment behaviour was observed when the polar surface energy was smaller than $2.05 \mathrm{~mJ}$ $\mathrm{m}^{-2}$, generated by the hydrophobic and long alkyl groups in the vanillin moiety. These results can guide the design of LC alignment layer based on polymer-containing bio-renewable resources.

\section{Conflicts of interest}

There are no conflicts to declare.

\section{Acknowledgements}

Financial supports by the Dong-A University Research Fund are gratefully acknowledged. 


\section{Notes and references}

1 S. Chandrasekhar, Liquid crystal, Cambridge University Press, Cambridge, 1992.

2 R. B. Meyer, Appl. Phys. Lett., 1968, 12, 281-282.

3 J. Stöhr, M. Samant, A. Cossy-Favre, J. Diaz, Y. Momoi, S. Odahara and T. Nagata, Macromolecules, 1998, 31, 19421946.

4 C. M. Rochman, M. A. Browne, B. S. Halpern, B. T. Hentschel, E. Hoh, H. K. Karapanagioti, L. M. Rios-Mendoza, H. Takada, S. The and R. C. Thompson, Nature, 2013, 494, 169-171.

5 L. Hu, G. Zheng, J. Yao, N. Liu, B. Weil, M. Eskilsson, E. Karabulut, Z. Ruan, S. Fan, J. T. Bloking, M. D. McGehee, L. Wagberg and Y. Cui, Energy Environ. Sci., 2013, 6, 513-518.

6 K. S. Mikkonen and M. Tenkanen, Food Sci. Technol., 2012, 28, 90-102.

7 T. Kohki, H. Masaki, K. Mitsuhiro, I. Nobutuki, H. Ray and S. Masanori, Alignment technology and application of liquid crystal devices, Taylor \& Francis, New York, 2005.

8 K. Ichimura, Chem. Rev., 2000, 100, 1847-1874.

9 J. Stohr and M. G. Samant, J. Electron. Spectrosc. Relat. Phenom., 1999, 98, 189-207.

10 M. Schadt, Annu. Rev. Mater. Sci., 1997, 27, 305-379.

11 N. Almeria and R. Paul, Chem. Rev., 2002, 102, 4139-4176.

12 M. Ree, Macromol. Res., 2006, 14, 1-33.

13 D. W. Berreman, Phys. Rev. Lett., 1972, 28, 1683-1687.

14 J. M. Geary, J. W. Goodby, A. R. Kmetz and J. S. Patel, J. Appl. Phys., 1987, 62, 4100-4108.

15 D. W. Berreman, Mol. Cryst. Liq. Cryst., 1973, 23, 215-231.

16 M. K. Ghosh and K. L. Mittal, Fundamentals and applications, Marcel Dekker, New York, 1996.

17 M. B. Feller, W. Chen and T. R. Shen, Phys. Rev. A, 1991, 43, 6778-6792.

18 N. A. J. M. van Aerle and A. J. W. Tol, Macromolecules, 1994, 27, 6520-6526.

19 K.-W. Lee, S.-H. Paek, A. Lien, C. Durning and H. Fukuro, Macromolecules, 1996, 29, 8894-8899.

20 K. Weiss, C. Woll, E. Hohm, B. Fiebranz, G. Forstmann, B. Peng, V. Scheumann and D. Johannsmann, Macromolecules, 1998, 31, 1930-1936.

21 R. Meister and B. Jerome, Macromolecules, 1999, 32, 480-486.

22 J. J. Ge, C. Y. Li, G. Xue, I. K. Mann, D. Zhang, S.-Y. Wang, F. W. Harris, S. Z. D. Cheng, S.-C. Hong and X. Zhuang, J. Am. Chem. Soc., 2001, 123, 5768-5776.

23 D. Kim, M. Oh-e and Y. R. Shen, Macromolecules, 2001, 34, 9125-9129.

24 K. E. Vaughn, M. Sousa, D. Kang and C. Rosenblatt, Appl. Phys. Lett., 2007, 90, 194102.
25 S. W. Lee, S. I. Kim, Y. H. Park, M. Reea, Y. N. Rim, H. J. Yoon, H. C. Kim and Y.-B. Kim, Mol. Cryst. Liq. Cryst., 2000, 349, 279-282.

26 Y. J. Lee, Y. W. Kim, J. D. Ha, J. M. Oh and M. H. Yi, Polym. Adv. Technol., 2007, 18, 226-234.

27 S. W. Lee, B. Chae, B. Lee, W. Choi, S. B. Kim, S. I. Kim, S.-M. Park, J. C. Jung, K. H. Lee and M. Ree, Chem. Mater., 2003, 15, 3105-3112.

28 S. B. Lee, G. J. Shin, J. H. Chi, W.-C. Zin, J. C. Jung, S. G. Hahm, M. Ree and T. Chang, Polymer, 2006, 47, 6606-6621.

29 H. Kang, J.-S. Park, D. Kang and J.-C. Lee, Polym. Adv. Technol., 2009, 210, 926-935.

30 H. Kang, T.-H. Kim, D. Kang and J.-C. Lee, Macromol. Chem. Phys., 2009, 210, 878-886.

31 U. Krings and R. G. Berger, Appl. Microbiol. Biotechnol., 2010, 49, 1-8.

32 L.-C. Chen, S.-J. Wu and C. Huang, Cosmet. Toiletries, 2010, 125, 34-39.

33 A. O. Barel, Handbook of cosmetic science and technology, CRC Press, Florida, 2009.

34 İ. Gülçin, J. Med. Food, 2011, 14, 975-985.

35 G. S. El-Baroy, H. H Abd El-Baky, R. S. Farag and M. A. Saleh, Afr. J. Biochem. Res., 2010, 4, 167-174.

36 A. Ultee, M. H. J. Bennik and R. Moezelaar, Appl. Environ. Microbiol., 2002, 68, 1561-1568.

37 D.-Y. Ryu, K. Shin, E. Drockenmuller, C. J. Hawker and T. P. Russell, Science, 2005, 308, 236-239.

38 C. D. Bain and G. M. Whitesides, J. Am. Chem. Soc., 1988, 110, 5897-5898.

39 D. K. Owens and R. W. Wendt, J. Appl. Polym. Sci., 1969, 13, 1741-1747.

40 U. Gedde, Polymer physics, Chapman and Hall, London, 1995.

41 R. A. Hayes, J. Appl. Polym. Sci., 1961, 5, 318-321.

42 B. Wesslen, R. Lenz, W. MacKnight and F. Karasz, Macromolecules, 1971, 4, 24-26.

43 J.-C. Lee, M. H. Litt and C. E. Rogers, J. Polym. Sci., Part B: Polym. Phys., 1998, 36, 75-83.

44 S. H. Paek, C. J. Durning, K. W. Lee and A. Lien, J. Appl. Phys., 1998, 83, 1270-1280.

45 B. S. Ban and Y. B. Kim, J. Appl. Polym. Sci., 1999, 74, 267271.

46 H. Y. Wu, C. Y. Wang, C. J. Lin, R. P. Pan, S. S. Lin, C. D. Lee and C. S. Kou, J. Phys. D: Appl. Phys., 2009, 42, 155303.

47 B. A. MacDonald, K. Rollins, D. Mackerron, K. Rakos, R. Eveson, K. Hashimoto and B. Rustin, Engineered films for display technologies, in Flexible flat panel displays, John Wiley \& Sons, West sussex, 2005. 